\title{
26. Water in the COVID-19 crisis: Response, recovery, and resilience
}

\author{
Claudia Sadoff and Mark Smith
}

COVID-19 has, like nothing that has gone before, revealed the "systems wiring" of the modern, globalized world, and how destructive disturbances to those systems can be. Water is a connector across these systems, and thus has critical implications both for the effectiveness of COVID-19 response efforts and for promoting growth and building resilience in a post-pandemic world.

\section{Water in response}

COVID-19 is shining a harsh spotlight on the inequalities, hardships, and global health risks that result from the collective failure to uphold the human right to water and sanitation. In many communities around the world, a lack of water supply and sanitation deprives people of their most basic protections against the spread of the virus.

Improving water, sanitation, and hygiene has the potential to prevent at least $9.1 \%$ of the global disease burden and $6.3 \%$ of all deaths, according to the World Health Organization (WHO) report Safer Water, Better Health, released before the pandemic. Nevertheless, 4.2 billion go without safe sanitation services and 3 billion lack basic hand-washing facilities. In addition, diarrheal diseases caused by waterborne pathogens and poor hygiene inhibit nutrient absorption, so that even those with access to adequate nutrition may face malnutrition. This means that where hand-washing is limited and waterborne illness is already common, not only will COVID-19 spread more easily, its lethality could be amplified.

We should also be cognizant of the gender implications. In many parts of the world, women and girls spend hours each day fetching water or waiting in crowded queues for water vendors, potentially increasing their risk of exposure to the virus. If they struggle with these tasks because they are ill, or have to care for the sick, their health and food security could be further compromised. Compounding the issue still further, restrictions on movement may lessen the ability to access water at all.

How can we respond to these problems? In the short term, governments and international organizations should work to ensure access to safe and reliable water supplies and sanitation. This includes emergency provision for underserved communities and taking care to protect women and girls responsible for fetching water from exposure. To address potential supply disruptions, we also need a clear understanding of where and how municipal or rural water infrastructure is coping with pandemic-related spikes in demand. In Ethiopia, the International Water Management Institute has research underway now to assess the implications of mitigation measures in rural communities. 


\section{Water in recovery}

Recovery from the pandemic will require effective water management that reinforces the stability of disrupted food systems. In some areas, lockdowns have impacted agricultural cycles - interrupting supplies of inputs, depressing demand, and keeping workers away from fields and factories. When farming activities resume, demand for irrigation water may rise quickly if dry season cropping expands to counter food supply deficits. Thus, a critical priority will be preparing for potentially significant unplanned irrigation withdrawals, making sure they do not undermine basic domestic water needs or overdraw aquifers, lakes, and rivers.

The risk of natural disasters - including drought, extreme weather, and flooding - occurring during the pandemic is another significant problem that threatens water security and long-term recovery. People displaced by disasters are typically relocated to densely populated camps or shelters where authorities may struggle to meet basic water, sanitation, and hygiene needs - and now, where the novel coronavirus could spread rapidly.

The prospect of overlapping shocks is yet another serious concern. The World Economic Forum 2020 Global Risks Report, published in January, ranked risks from water crises higher than either infectious diseases or food crises. In 2020, there will likely be places where we see all three at once.

To address such risks, countries will need to reinforce water governance to ensure the reliable delivery of water for priority uses, enhance water storage and irrigation capacity to head off potential crop failures and compensate for disruptions to rainfed agricultural cycles, and reduce unmanaged competition for water.

This also means better preparation for droughts or floods to mitigate the multiple shocks they can deliver to food systems. Fortunately, we can now monitor and forecast water-related risks and authorities can use those data to reduce risks of water-related setbacks to recovery, and introduce services like index-based weather insurance that will support the livelihoods of the poorest and most vulnerable people if floods or droughts strike.

\section{Water in resilience}

In the post-pandemic world, we must use what we are learning about the dynamics of these interconnected systems to "build back better." Investments in water should be used to build greater resilience to climate, health, and food system shocks, and more effective management of water-related risks.

Building back better means constructing more resilient water, sanitation, and hygiene systems that will deliver these fundamental services despite the hydrological uncertainties of climate change and growing water scarcity and pollution. It means building more "circular" water systems that secure supplies and better capture, clean, and reuse water resources in ways that protect human and ecosystem health. It means reimagining our "waste streams" as "resource streams": instead of releasing $80 \%$ of the world's wastewater back into the environment untreated, we should invest in wastewater treatment that will provide the double win of protecting communities and ecosystems against biological hazards while safely recycling water, energy, and nutrient resources. While there is currently 
no evidence that COVID-19 can be spread through water or wastewater, we do know that historically many epidemics have spread this way, and that untreated wastewater remains a health hazard in too many communities today.

It also means ensuring that food production and trading systems are more resilient to water challenges. To bolster domestic food supplies from COVID-19 disruptions, some countries have restricted exports and/or changed patterns of agricultural production. In addition to potential impacts on global prices, poverty, and hunger, such moves can affect water availability and undermine the resilience of food systems. Water availability and how it is allocated to multiple uses must be accounted for in food system transformations in different locations with varying geographies. Appropriate accounting for water in agricultural trade and production policies and investments is critical to sustainability. Water-scarce regions can import water-intensive crops (and their "virtual" water) from water-rich regions, where their production is sustainable and does not compete for drinking water or ecosystem requirements.

As governments and international organizations work to address these complex, overlapping challenges, systems thinking is crucial. Water connects health, food systems, climate change, nature, energy, and finance. The fabric of water security is created by weaving together effective governance, knowledge, and skills, connectivity across systems, and investment in and application of infrastructure, technologies, and services from ecosystems. The COVID-19 pandemic is stressing all of these, forcing a reckoning with many underlying problems in the process. But it is also an opportunity to expand our understanding of how these systems work and how we can build back better in a post-pandemic world.

Originally published June 4, 2020. 